\title{
Diagnostic profile of inpatients as a determinant of length of stay in a general hospital psychiatric unit
}

J.E.C. Hallak ${ }^{1,3}$,

J.A.S. Crippa ${ }^{1,2}$,

G. Vansan ${ }^{1}$ and A.W. Zuardi ${ }^{1}$
Correspondence

A.W. Zuardi

Departamento de Neurologia,

Psiquiatria e Psicologia Médica FMRP, USP

Av. Bandeirantes, 3900

14049-900 Ribeirão Preto, SP

Brasil

Fax: +55-16-635-0713

E-mail: awzuardi@fmrp.usp.br

Publication supported by FAPESP. $\ldots \ldots \ldots \ldots \ldots \ldots$

Received August 5, 2002

Accepted May 6, 2003

\author{
'Departamento de Neurologia, Psiquiatria e Psicologia Médica, \\ Faculdade de Medicina de Ribeirão Preto, Universidade de São Paulo, \\ Ribeirão Preto, SP, Brasil \\ ${ }^{2}$ Department of Psychological Medicine, Institute of Psychiatry, \\ University of London, London, UK \\ ${ }^{3}$ Department of Psychiatry and Behavioural Sciences, \\ University of Manchester, Manchester, UK
}

\section{Abstract}

The aim of this study was to determine if the diagnostic profile of inpatients of a psychiatric unit in a general hospital influences the length of stay. The results of a retrospective survey comprising the first 16 years of operation of the Psychiatric Unit of the Ribeirão Preto General Hospital (PURP) showed that the progressive increase observed in the length of stay correlated with the increase in percentage of schizophrenia diagnosis, after the 8th year of hospital operation, and of affective disorders, after the 12th year. The length of hospitalization kept increasing until the 16th year, even though there was no change in the diagnostic profile of the patients admitted to the unit. In a prospective study encompassing the next six months, 61 inpatients were evaluated with the Structured Clinical Interview for DSM-III-R and the Brief Psychiatric Rating Scale (BPRS). The results showed that $82 \%$ of the inpatients fulfilled the diagnostic criteria for the schizophrenic or affective disorder spectrum at admission, with a discharge rate slower than for other diagnoses, although the length of hospitalization did not significantly differ among diagnostic categories. The results further demonstrated that in every diagnostic category more than $50 \%$ of the patients stayed in hospital for more than one week after reaching a BPRS score equal to 6 , indicative of discharge. Overall, these data suggest that the increase in length of hospitalization may be due to a higher percentage of patients with a diagnosis of schizophrenia and affective disorder admitted to the PURP. In addition, patients with low symptomatic levels remained in hospital longer than they should have.
Key words

- Psychiatric unit

- General hospital

- Diagnostic category

- Length of stay 


\section{Introduction}

Mainly as a consequence of the movement for psychiatric reform, great emphasis is being currently placed on noninstitutional methods to treat psychiatric disorders, among them the setting up of psychiatric units in general hospitals (PUGHs) $(1,2)$. With the proliferation of PUGHs in the United States, there was strong pressure to reduce the length of hospitalization. In the early 80 's, the average length of time psychiatric patients stayed in general hospitals was about 18 to 20 days, and when the period was extended beyond 27 days, the hospital was not compensated for the extra days (3). In general, 28 days was considered as an adequate length of stay for psychiatric patients in general hospitals (4).

There has been a progressive increase in the length of hospitalization, though most investigators still believe 15 to 30 days is adequate for PUGHs (5). Only 50\% of hospitalizations longer than 30 days are medically justified. Another $39.7 \%$ are due to social and administrative factors beyond the psychiatrist's control, and $10.3 \%$ are medically unacceptable.

Most patients hospitalized for more than 30 days had a diagnosis of schizophrenia or affective disorder (6). It is thus possible that a change in diagnostic profile is increasing the length of stay in PUGHs. In this regard, Olfson (7) reported an increasing rate of severe psychiatric disorders (major depression, schizophrenia and other functional psychoses) among patients discharged from PUGHs during the last 10 years.

The aim of the present study was to determine whether diagnostic category and severity of psychopathology affect the length of hospitalization, by analyzing the diagnostic profile, severity of symptoms and length of stay of patients admitted to the Psychiatric Unit of the Ribeirão Preto General Hospital (PURP).

\section{Material and Methods}

\section{Retrospective study}

Medical records of PURP inpatients collected during the earlier 16 years of its operation (July 1978 to June 1994) were analyzed as to diagnosis and length of hospitalization. Only diagnosis recorded at discharge according to the International Classification of Diseases, version 9, was considered for analysis.

\section{Follow-up study}

Subjects. Patients admitted to the PURP along the second semester of 1994, who agreed to participate in the study, were evaluated. Of 66 patients, 5 were excluded: 3 were discharged during the first week of hospitalization and 2 were transferred to other units of the hospital for medical reasons. Table 1 shows the demographic characteristics of the 61 patients studied. The Ethics Committee of the Institution approved the study protocol and informed consent was obtained from all patients.

\section{Procedure}

Patients were diagnosed with the Structured Clinical Interview for DSM-III-R, patient version (8), which was translated into Portuguese and validated by Del Ben et al. (9). When the patient did not fit any diagnostic category of this instrument, the SCID-II for personality disorder was applied (10). The interview was performed by a psychiatrist trained in the use of SCID, during the 2 nd or 3 rd week of hospitalization.

The Brief Psychiatric Rating Scale (BPRS), modified by Bech et al. (11), and translated and adapted to Portuguese by Zuardi et al. (12), was used in order to follow the patients' level of symptoms. The BPRS was first applied between the 1st and the 3rd day of hospitalization, and then weekly 
throughout the duration of hospitalization.

The scales were applied by a specifically trained psychiatrist whose performance was assessed by reliability tests applied before as well as during the study. For the BPRS, an intraclass correlation coefficient of 0.67 was obtained (15 of 18 items $>0.4$ ), and for the SCID a weighted kappa of 0.8 was obtained. Both values were significant at $\mathrm{P} \leq 0.05$. The evaluators were unaware of the patients' medical records.

\section{Analysis of results}

In the retrospective study, the change in diagnostic categories along time was analyzed by $\chi^{2}$ tests. One-way analysis of variance (ANOVA) was used for length of stay.

In the follow-up study, patients were grouped into seven diagnostic categories according to the SCID-P, namely major depression, mania, schizophrenia, schizoaffective disorder, organic-mental disorder, other psychotic disorders (OPD), and other nonpsychotic diagnoses (ONP).

A curve of decay for each diagnostic category was obtained from the number of patients remaining hospitalized during the successive 27 weeks. Straight regression lines were calculated from the same data using the least squares method, and their slopes were compared. Two lines were different when their angular coefficients were outside each other's $95 \%$ confidence interval $(95 \% \mathrm{CI})$.

One-way ANOVA was used to compare diagnostic categories with respect to BPRS initial rating, length of stay and delay to reach the BPRS rating predictive of discharge. The results of a previous study showed that a BPRS score of 6 predicts discharge within one week (12).

Pearson's correlation coefficient was used to assess the correlation between BPRS rating and length of stay.

Statistical analysis was performed using the SPSS statistical package. For every anal- ysis, the level of significance was set at $\mathrm{P} \leq 0.05$.

\section{Results}

\section{Retrospective study}

The percentage of patients with a diagnosis of schizophrenia and affective disorder as well as the average length of stay during the 1st, 4th, 8th, 12th and 16th years of PURP operation are shown in Figure 1. There was a significant increase in length of stay along this period of time (ANOVA: $\mathrm{F}_{6,54}=$ 8.56; $\mathrm{P}<0.001)$, as well as a significant rise in the percentage of patients with diagnoses of schizophrenia $\left(\chi^{2}=38.31\right.$; d.f. $=4$; $\mathrm{P}<$ $0.001)$ and affective disorder $\left(\chi^{2}=25.55\right.$; d.f. $=4 ; \mathrm{P}<0.001)$. It may be seen in Figure 1 that the increase in both the length of stay and diagnosis of schizophrenia occurred from the 8th year on, whereas the increase in diagnosis of affective disorder occurred from the 12 th year onwards.

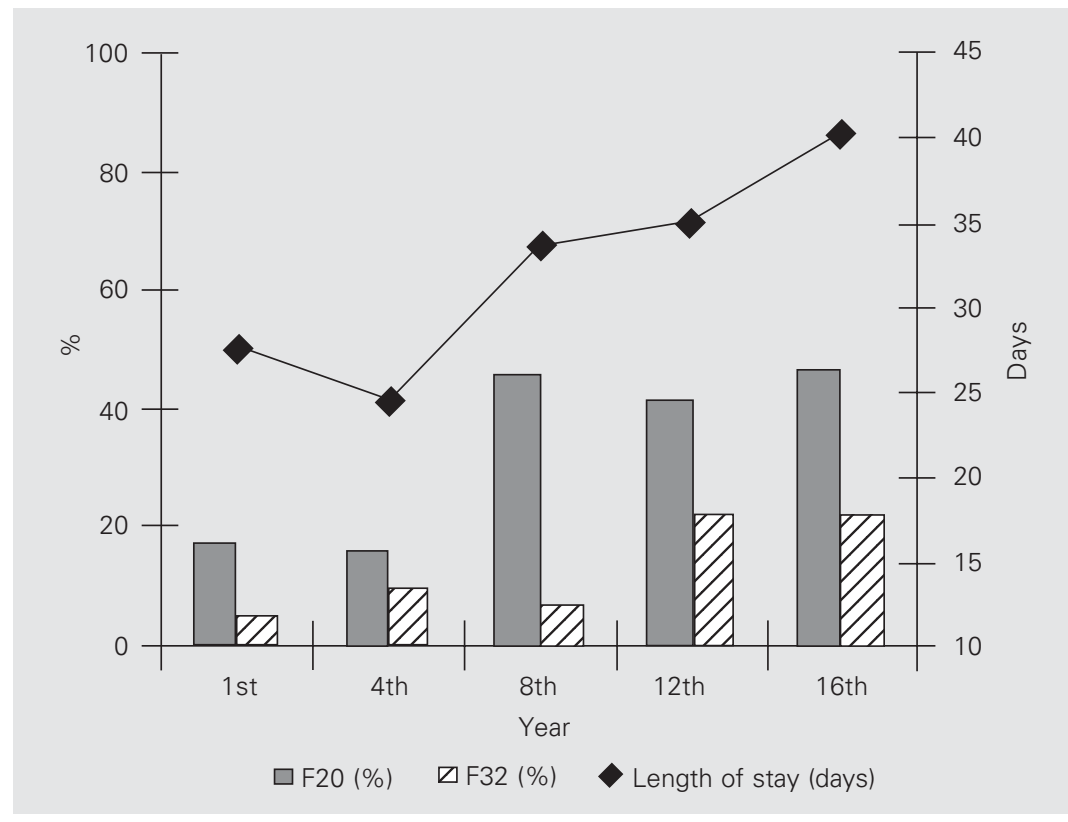

Figure 1. Percentage of patients with schizophrenia (F20) and affective disorder (F32) and average length of stay in the Psychiatric Unit of the Ribeirão Preto General Hospital, during the $1 \mathrm{st}, 4$ th, 8 th, 12 th and 16 th years of operation. 


\section{Follow-up study}

The number of patients in each diagnostic category was: schizophrenia $(\mathrm{N}=19)$, mania $(\mathrm{N}=12)$, major depression $(\mathrm{N}=11)$, schizoaffective disorder $(\mathrm{N}=8)$, organic-mental disorder $(\mathrm{N}=4), \mathrm{ONP}(\mathrm{N}=4)$, and OPD ( $\mathrm{N}$ $=3$ ). There was a marked predominance of patients within the schizophrenic and affective disorders spectrum ( $82 \%$ of total).

Figure 2 shows the percent decrease in the number of inpatients as a function of the weeks of hospitalization in each diagnostic category. The linear fit of the regressions was significant $(\mathrm{P}<0.001)$, though for major depression and schizoaffective diagnoses fit to an exponential function was better. Nevertheless, linear regression was used in all categories to facilitate comparisons. The diagnostic category mania differed from all others $(\mathrm{a}=-3.12 ; 95 \% \mathrm{CI}=-3.98$ to -2.26$)$, the same occurring for the category major depression $(\mathrm{a}=-7.14 ; 95 \% \mathrm{CI}=-8.22$ to -6.05). The schizophrenia $(\mathrm{a}=-10.86 ; 95 \% \mathrm{CI}$ $=-12.69$ to -9.02$)$ and schizoaffective $(\mathrm{a}=$ -12.05 ; $95 \% \mathrm{CI}=-14.68$ to -9.42 ) categories did not differ from each other, but differed from the remaining categories. There was no difference between the organic-mental disorder $(\mathrm{a}=-15.48 ; 95 \% \mathrm{CI}=-20.04$ to -10.91$)$ and the OPD $(\mathrm{a}=-20.03 ; 95 \% \mathrm{CI}=-28.15$ to -11.91) and ONP categories $(\mathrm{a}=-20.71$; $95 \% \mathrm{CI}=-28.23$ to -13.20$)$.

Table 2 shows that the average length of stay did not differ significantly among diagnostic categories (ANOVA: $\mathrm{F}_{6,54}=1.55 ; \mathrm{P}=$ 0.181).

ANOVA showed that schizophrenic and schizoaffective patients presented significantly higher BPRS scores than the other groups, whereas the scores for the group that included personality disorders and alcoholism were significantly lower than those for the other diagnostic groups $\left(\mathrm{F}_{6,54}=4.015 ; \mathrm{P}=\right.$ 0.002; Table 3). There was no significant correlation (Pearson's correlation coefficient $=0.17 ; \mathrm{P}=0.193$ ) between the initial value of the BPRS and length of hospitalization, meaning that patients who were more symptomatic at admission did not necessarily stay longer in hospital. In contrast, percent decline in BPRS score along the first two weeks of hospitalization (Table 4) was significantly correlated with the length of stay (Pearson's correlation coefficient $=0.40$; $\mathrm{P}=0.002$ ).
Figure 2. Percentage of patients hospitalized during 27 weeks of observation from the following diagnostic groups: major depression (F32), mania (F30), schizophrenia (F20), schizoaffective disorder (F25), organic-mental disorder (F09), other psychotic disorders (OPD), other nonpsychotic diagnoses (ONP). The inset shows the regression lines calculated from the same data. Statistically similar linear regressions are represented by the same type of line.

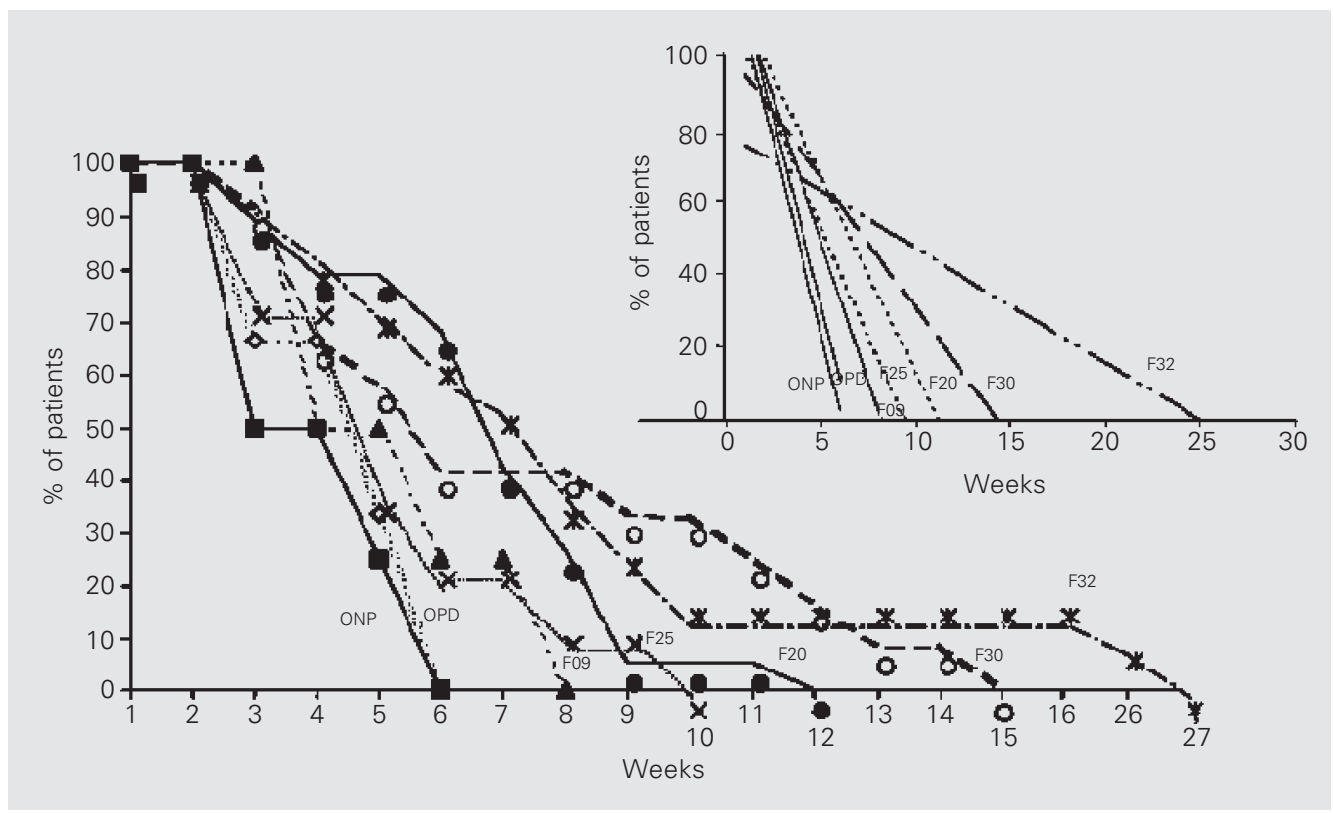


Table 2 shows the length of stay until discharge criterion (BPRS score of 6) for each diagnosis, as well as the percentage of patients who were discharged before fulfilling this criterion and the percentage of patients who stayed in hospital for more than one week after fulfilling this criterion. It may be seen that the length of stay until the criterion was fulfilled did not differ significantly among the diagnoses $\left(\mathrm{F}_{6,54}=1.39 ; \mathrm{P}=\right.$ 0.23 ). Fifty to $100 \%$ of the patients remained in hospital for more than one week after reaching the criterion for discharge.

\section{Discussion}

The results of the present retrospective study suggest a positive correlation between the increase in the percentage of schizophrenia and affective disorder diagnoses and the increase in average length of stay. In fact, during the 8th year of the operation of the unit, the length of stay began to increase and at the same time there was a rise in the percentage of schizophrenia, and from the 12th year on, in the percentage of affective disorder. Nevertheless, this may not be the only factor influencing the length of stay because from the 12th to the 16th year there was no change in the percentage of schizophrenia or affective disorder diagnoses, but the average length of stay continued to rise. It is possible that the latter is due to increased
Table 1. Demographic characteristics of $61 \mathrm{pa}-$ tients admitted to the Psychiatric Unit of the Ribeirão Preto General Hospital during the second semester of 1994.

\begin{tabular}{|c|c|c|}
\hline & Number & Percentage \\
\hline \multicolumn{3}{|l|}{ Gender } \\
\hline Female & 39 & 63.9 \\
\hline Male & 22 & 36.1 \\
\hline \multicolumn{3}{|l|}{ Ethny } \\
\hline White & 40 & 65.6 \\
\hline Mixed & 15 & 24.6 \\
\hline Black & 5 & 8.2 \\
\hline Asian & 1 & 1.6 \\
\hline \multicolumn{3}{|l|}{ Marital status } \\
\hline Married & 25 & 41.0 \\
\hline Single & 35 & 57.4 \\
\hline Divorced & 1 & 1.6 \\
\hline \multicolumn{3}{|l|}{ Education } \\
\hline Illiterate & 3 & 4.9 \\
\hline 1st Incomplete & 41 & 67.3 \\
\hline 1st Complete & 3 & 4.9 \\
\hline 2nd Incomplete & 5 & 8.2 \\
\hline 2nd Complete & 5 & 8.2 \\
\hline 3rd Incomplete & 3 & 4.9 \\
\hline 3rd Complete & 1 & 1.6 \\
\hline \multicolumn{3}{|l|}{ Age (years) } \\
\hline$<25$ & 27 & 42.26 \\
\hline $26-35$ & 12 & 19.67 \\
\hline $36-45$ & 11 & 18.03 \\
\hline $46-55$ & 6 & 9.83 \\
\hline $56-65$ & 4 & 6.56 \\
\hline$\geq 66$ & 1 & 1.64 \\
\hline \multicolumn{3}{|c|}{ Previous hospitalizations } \\
\hline 0 & 37 & 60.7 \\
\hline 1 & 8 & 13.1 \\
\hline 2 & 6 & 9.8 \\
\hline$\geq 3$ & 10 & 16.4 \\
\hline
\end{tabular}

1st, primary school; 2nd, secondary school; 3rd, high school.

Table 2. Length of stay of patients admitted to the Psychiatric Unit of the Ribeirão Preto General Hospital during the second semester of 1994 as a function of diagnosis and discharge criterion (BPRS score $\leq 6$ ).

\begin{tabular}{lcccc}
\hline Diagnosis & $\begin{array}{c}\text { Days spent in hospital } \\
\text { (mean } \pm \text { SEM) }\end{array}$ & $\begin{array}{c}\text { Weeks until criterion } \\
\text { (mean } \pm \text { SEM) }\end{array}$ & $\begin{array}{c}\text { Patients not reaching } \\
\text { criterion at discharge (\%) }\end{array}$ & $\begin{array}{c}\text { Patients hospitalized beyond one } \\
\text { week after criterion (\%) }\end{array}$ \\
\hline Schizophrenia & $44.16 \pm 15.64$ & $35.1 \pm 18.1$ & 26.3 & 64.3 \\
Schizoaffective disorder & $35.88 \pm 16.12$ & $22.4 \pm 11.2$ & 12.5 & 71.4 \\
Major depression & $67.09 \pm 58.15$ & $54.2 \pm 61.3$ & 27.7 & 62.5 \\
Mania & $49.92 \pm 29.17$ & $38.5 \pm 30.0$ & 16.7 & 70.0 \\
Organic-mental disorder & $35.5 \pm 13.48$ & $19.8 \pm 12.6$ & 25.0 & 100.0 \\
Other psychotic disorders & $30.67 \pm 10.07$ & $12.8 \pm 4.8$ & 0 & 50.0 \\
Other nonpsychotic diagnoses & $26.25 \pm 9.67$ & $17.0 \pm 2.9$ & 0 & 66.7 \\
\hline
\end{tabular}

BPRS: Brief Psychiatric Rating Scale. 
severity of symptoms, but there is no empirical evidence to support this hypothesis. One limitation of the present study is that the diagnoses, which were taken from medical records, were made without standardization criteria.

The results of the follow-up study confirm the predominant number of patients ( $82 \%$ of total) with disorders in the schizophrenic and affective spectrum - schizophrenia, schizoaffective disorder, major depression and mania - among the inpatients of the PURP during the 6-month observation period. Furthermore, the regression lines representing the decline of hospitalized patients in each diagnostic category over the 27 weeks studied were less steep for patients with disorders in the schizophrenic and affective spectrum than for patients with other diag-

Table 3. Brief Psychiatric Rating Scale evaluation of patients admitted to the Psychiatric Unit of the Ribeirão Preto General Hospital during the second semester of 1994.

\begin{tabular}{lrrr}
\hline Diagnosis & $N$ & \multicolumn{2}{c}{ Score (mean \pm SEM) } \\
\cline { 3 - 4 } & & Admission & Discharge \\
\hline Schizophrenia & 19 & $24.36 \pm 7.1$ & $5.00 \pm 5.7$ \\
Major depression & 11 & $17.09 \pm 6.0$ & $3.41 \pm 5.1$ \\
Mania & 12 & $18.00 \pm 7.0$ & $2.75 \pm 2.7$ \\
Schizoaffective disorder & 8 & $23.25 \pm 9.6$ & $3.75 \pm 4.2$ \\
Organic-mental disorder & 4 & $17.25 \pm 5.0$ & $8.25 \pm 5.5$ \\
Other psychotic disorders & 3 & $13.68 \pm 9.0$ & $1.33 \pm 1.2$ \\
Other nonpsychotic diagnoses & 4 & $9.75 \pm 2.2$ & $0.50 \pm 0.6$
\end{tabular}

Table 4. Brief Psychiatric Rating Scale evaluation during the first two weeks of hospitalization.

\begin{tabular}{|c|c|c|c|c|c|}
\hline \multirow[t]{2}{*}{ Diagnosis } & \multicolumn{3}{|c|}{ Mean score } & \multicolumn{2}{|c|}{ ANOVA } \\
\hline & 1st day & 7th day & 15th day & $\mathrm{F}$ & $P$ \\
\hline Schizophrenia & 24.36 & 17.68 & 14.84 & $F_{2,54}=5.48$ & $0.007^{*}$ \\
\hline Major depression & 17.09 & 13.27 & 9.72 & $F_{2,30}=2.76$ & 0.080 \\
\hline Mania & 18 & 11.42 & 9.08 & $F_{2,33}=5.07$ & $0.012^{*}$ \\
\hline Schizoaffective disorder & 23.25 & 13.62 & 7.50 & $F_{2,21}=8.82$ & $0.002^{*}$ \\
\hline Organic-mental disorder & 17.25 & 7.75 & 6.75 & $F_{2,9}=6.49$ & $0.018^{*}$ \\
\hline Other psychotic disorders ${ }^{1}$ & 13.68 & 6.33 & 3.00 & - & - \\
\hline Other nonpsychotic diagnoses ${ }^{1}$ & 19.75 & 3.25 & 1.25 & - & - \\
\hline
\end{tabular}

${ }^{1} \mathrm{~N}$ insufficient for ANOVA. ${ }^{*} \mathrm{P}<0.05$ comparing $1 \mathrm{st}, 7$ th and 15 th days (ANOVA). noses. This indicates a longer hospital stay for the former categories. Nevertheless, the average length of stay did not show any statistically significant difference among different diagnoses. This discrepancy may be due to the fact that in groups with certain diagnoses, only some patients stayed in hospital for longer periods, a fact that lengthened the end of the curve. This was most clear for major depression, whose data fitted better an exponential curve than a straight line because of the long length of stay of two patients with resistant depression.

Taken together, the present retrospective and follow-up studies indicate that the relatively prolonged hospitalization observed in the last years of operation of the PURP (average of 44.62 days during the 16th year) may be due, at least in part, to a higher percentage of patients with schizophrenia and affective disorder admitted to the hospital. Similar changes in diagnostic profile of patients hospitalized in PUGHs have been described in other countries (7). A likely explanation for this trend may be the progressive reduction of beds in traditional psychiatric hospitals, which directs the patients to general hospitals. In the last three decades, the place where the mentally ill are treated has been steadily moving from the psychiatric to the general hospital (1). For instance, in the United States, between 1969 and 1981 treatment of episodes of mental illness increased by $28.4 \%$ in general hospitals, whereas it decreased by $34.9 \%$ in psychiatric institutions (13). Although this reduction of beds in psychiatric hospitals affected several aspects of psychiatric management, its major impact was on PUGHs $(14,15)$.

However, this explanation does not seem to apply to the present results. Although in the catchment area of the PURP, 330 beds of psychiatric hospitals (30\% of total) were eliminated between 1991 and 1994 (16), due to changes in psychiatric care policy, this period corresponds to the last four years of 
the study, when the number of patients with diagnoses of schizophrenia and affective disorder had already stabilized. Since the length of hospitalization kept increasing during this period, one may speculate that the reduction of psychiatric beds in the catchment area might have aggravated the condition of patients admitted to the PURP.

The current increased severity of patients treated at PUGHs should motivate a reappraisal of the ideal length of stay and/or a revision of extra-hospital care programs (dayhospitals, psychosocial rehabilitation centers, etc.). Even though a wealth of studies shows that there is no advantage in longterm hospitalization, the minimum length of effective hospitalization as a function of diagnosis has not yet been established $(6,17$, 18). Nevertheless, there are studies suggesting that certain patients need longer periods of hospitalization than others, and when hospitalization is short they pose higher demand on the support network (17). Therefore, because of the recent changes in the profile of patients admitted to PUGHs, it should be carefully evaluated whether the current pressure for extremely short hospitalization may result in the discharge of patients still in severe symptomatic conditions. This suspicion has been raised by reported observations showing that among patients seen at PUGHs who underwent a dramatic reduction in length of hospitalization, the rate of readmission became $125 \%$ higher than in the previous 3 years (3).

The present study also points out another factor that may be contributing to prolonged hospitalization. Depending on the diagnostic category, 50 to $100 \%$ of the patients stayed in hospital longer than one week after reaching the BPRS score predictive of discharge. Thus, patients are staying longer in the PURP than justified by the level of their symptoms. This may be due to the fact that PURP is part of a teaching hospital where supervised resident students regularly treat patients. As in other Brazilian university hospitals, psychiatric residents usually do clinical evaluation of patients as part of their training. They then report to a supervisor - an experienced clinician - in order to establish the diagnosis and set up a treatment program. It is thus assumed that, because of their expert knowledge about psychiatric diagnosis, supervisors are able to detect mistakes occasionally made by residents when collecting, interpreting and organizing information, even when they do not examine the patients themselves (19). Nevertheless, a study comparing patients interviewed under direct supervision with others interviewed by residents under traditional supervision revealed that the former procedure led to a more precise diagnosis and higher commitment to treatment than the latter. With traditional supervision there was a tendency to overestimate pathology and to have a pessimistic attitude towards the patient, due to incomplete case presentation and the fact that residents usually make more severe diagnoses than experienced clinicians (20).

\section{References}

1. Fisher $W H$, Dorwart RA, Schlesinger $M$, Epstein $S$ \& Davidson $H$ (1992). The role of general hospitals in the privatization of inpatient treatment for serious mental illness. Hospital and Community Psychiatry, 43: 1114-1119.

2. Botega NJ \& Dalgalarrondo P (1993). Saúde Mental no Hospital Geral: Espaço para o Psíquico. Hucitec, São Paulo, SP, Brazil.

3. Pepper B (1991). Power and governance issues in general hospital psychiatry. Hospital and Community Psychiatry, 42: 1169-1172.

4. Kirshner LA (1982). Length of stay of psychiatric patients: a critical review and discussion. Journal of Nervous and Mental Disease, 170: 27-33

5. Appleby L, Desai PN, Luchins DJ, Gibbons RD \& Hedeker DR (1993). Length of stay and recidivism in schizophrenia: a study of public psychiatric hospital patients. American Journal of Psychiatry, 150: $72-76$

6. Mai FM, Gosselin J, Varan L, Bourgon L \& Navarro JR (1993). Effects of treatment and alternative care on length of stay on a general hospital psychiatric unit - results of an audit. Canadian 
Journal of Psychiatry, 38: 39-45.

7. Olfson M (1991). General hospitals and the severely mentally ill: changing patterns of diagnosis. American Journal of Psychiatry, 148: 892-897.

8. Spitzer RL, Williams JR, Gibbon M \& First MB (1990). Structured Clinical Interview for DSM-III-R - Patient Edition (SCID-P, version 1.0). American Psychiatric Press, Washington DC

9. Del Ben CM, Rodrigues CRC \& Zuardi AW (1996). Reliability of the Portuguese version of the structured clinical interview for DSM-III-R (SCID) in a Brazilian sample of psychiatric outpatients. Brazilian Journal of Medical and Biological Research, 29: 1675-1682.

10. Spitzer RL, Williams JR, Gibbon M \& First MB (1989). Structured Clinical Interview for DSM-III-R Personality Disorders (SCID-II, 9/1/ 89 version). Biometrics Research Department, New York State Psychiatric Institute, New York.

11. Bech P, Kastrup M \& Rafaelsen OJ (1986). Mini-compendium of rating scales for states of anxiety, depression, mania and schizophrenia with corresponding DSM-III syndromes. Acta Psychiatrica Scandinavica, 326 (Suppl): 7-37.

12. Zuardi AW, Loureiro SR, Rodrigues CRC, Correa AJ \& Glock SS (1994). Estudo da estrutura fatorial, fidedignidade e validade da tradução e adaptação para o português da Escala de Validação Psiquiátrica Breve (BPRS) Modificada. Revista da Associação Brasileira de Psi- quiatria e Associação Psiquiátrica da América Latina, 16: 63-68.

13. Goldman HH, Taube CA \& Jencks SF (1987). The organization of the psychiatric inpatient service system. Medical Care, 25: 6-21.

14. Bachrach LL (1981). The effects of deinstitutionalization on general hospital psychiatry. Hospital and Community Psychiatry, 32: 786790.

15. Greenhill MH (1979). Psychiatric units in general hospitals: 1979 Hospital and Community Psychiatry, 30: 169-182.

16. Del Ben CM, Marques JMA, Sponholz A \& Zuardi AW (1999). Políticas de saúde mental e mudanças na demanda de serviços de emergência. Revista de Saúde Pública, 33: 470-476.

17. Hirsch SR, Platt S, Knights A \& Weyman A (1979). Shortening hospital stay for psychiatric care: effect on patients and their families. British Medical Journal, 1: 442-446.

18. Sytema S, Laciga J, Giel R \& Prevratil V (1992). Inpatient care in an eastern and a western European area - a comparative case register study. Social Psychiatry and Psychiatric Epidemiology, 27: 274-279.

19. Spitzer RL, Skodol AE, Williams JBW, Gibbon M \& Kass F (1982). Supervising intake diagnosis. A psychiatric "Rashomon". Archives of General Psychiatry, 39: 1299-1305.

20. Jaynes S, Charles E, Kass F \& Holzman S (1979). Clinical supervision of the initial interview: effects on patient care. American Journal of Psychiatry, 136: 1454-1457. 